\title{
Um Estudo Exploratório da Aplicação de Pensamento Computacional Baseado nas Perspectivas de Professores do Ensino Médio
}

\author{
Ahemenson Fernandes Cavalcante ${ }^{1}$, Leonardo dos Santos Costa ${ }^{1}$, \\ Ana Liz Souto O. Araújo ${ }^{12}$, Wilkerson L. Andrade ${ }^{2}$, Dalton D. Serey Guerrero \\ ${ }^{1}$ Departamento de Ciências Exatas - Universidade Federal da Paraíba \\ Rua da Mangueira, s/n, Companhia de Tecidos Rio Tinto \\ 58.297-000 - Rio Tinto - PB - Brasil \\ ${ }^{2}$ Laboratório de Práticas de Software - Universidade Federal de Campina Grande \\ Av. Aprígio Veloso, s/n, SPLab, Bodocongó \\ 58429-900 - Campina Grande - PB - Brasil \\ \{leonardo, ahemenson, analiz\}@dcx.ufpb.br, \\ \{wilkerson, dalton\}@computacao.ufcg.edu.br
}

\begin{abstract}
This paper aims to know the perception of computational thinking abilities by teachers. We carried out a survey and interviews with the public school teachers. The collected data were analyzed qualitatively based on the definitions of the literature. The results pointed out that the computational thinking abilities have been few explored.
\end{abstract}

Resumo. Este trabalho tem como objetivo conhecer a percepção de professores do Ensino Médio a respeito da aplicação de habilidades do pensamento computacional em sua prática docente. Realizamos uma pesquisa de campo com professores de uma escola pública, na qual aplicamos questionários (survey) e realizamos entrevistas. Os dados coletados foram analisados qualitativamente, comparando as definições da literatura e as respostas do survey e da entrevista. Com base nos resultados, temos indícios de que as habilidades do pensamento computacional ainda são pouco exploradas no grupo de professores pesquisados.

\section{Introdução}

Os impactos causados pela tecnologia na sociedade fizeram requerer da escola muito mais do que o ensino de conteúdos. A fez repensar como trabalhar diversas competências que são exigidas neste século, entre elas, as competências relacionadas à computação. Blinkstein (2008) acredita que a lista de habilidades exigidas para este século é bem extensa. Porém, ele enfatiza o pensamento computacional com sendo uma das mais significativas, como também a menos compreendida. 
VI Congresso Brasileiro de Informática na Educação (CBIE 2017)

Anais dos Workshops do VI Congresso Brasileiro de Informática na Educação (WCBIE 2017)

Pensamento computacional pode ser compreendido como um processo de resolução de problemas que inclui conceitos, habilidades e práticas da Ciência da Computação (Wing, 2006). Wing (2006) argumenta ainda que a sua utilização direciona a solucionar problemas nos mais diversos campos do conhecimento, não sendo exclusiva para profissionais da computação.

Diante dessas premissas, diversos trabalhos vêm desenvolvendo o pensamento computacional nas escolas do Brasil. Scaico et al. (2012) buscaram propagar conceitos da computação nas escolas públicas, utilizando de minicursos para abordarem tais fundamentos com e sem o uso do computador. Já Vieira, Passos e Barreto (2013) visaram inovar na forma de inserção desses fundamentos da computação, se utilizando de técnicas teatrais junto com computação desplugada para propagar os fundamentais da computação nas escolas públicas. Campos et al. (2014) utilizaram atividades com números binários cujo o objetivo foi trabalhar conceitos de abstração e representação de dados.

Essas iniciativas, no intuito de explorar esses conceitos e competências da computação, partiram do âmbito de projetos universitários. São escassos os trabalhos que nos apresentam iniciativas feitas por professores da educação básica. Mesmo sendo possível a inserção de conceitos e práticas da computação, como o pensamento computacional, em sala de aula, com ou sem o uso do computador, são poucas as pesquisas que investigam iniciativas que sejam originados desses professores. Nesse sentindo, desconhecemos se os professores da educação básica possuem ciência dessas habilidades ou se as exploram em suas práticas pedagógicas; também não sabemos qual a visão deles acerca desses conceitos. Assim, é importante investigar quais são as suas percepções sobre o pensamento computacional, uma vez que, os professores da área da computação defendem que as habilidades desenvolvidas com o pensamento computacional podem ser trabalhadas nas mais diferentes áreas do conhecimento, possibilitando assim, uma maior integração sobre diversas disciplinas em sala de aula.

Este trabalho inicial e exploratório tem o objetivo de conhecer a percepção dos professores do Ensino Médio sobre o pensamento computacional e analisar se as atividades desenvolvidas por eles auxiliam no desenvolvimento dessas habilidades nos alunos. Levantamos as seguintes questões de pesquisa: Qual a percepção dos professores do Ensino Médio sobre o uso das habilidades do pensamento computacional na prática docente? As atividades desenvolvidas pelos professores auxiliam no desenvolvimento do pensamento computacional?

Para responder as questões de pesquisa, iniciamos com uma revisão bibliográfica a respeito do pensamento computacional na educação básica. Em seguinda, planejamos e realizamos um survey com professores do Ensino Médio de uma escola pública no intuito de identificar qual a percepção que eles tinham das habilidades do pensamento computacional em sua prática pedagógica. Por último, entrevistamos seis desses professores com o propósito de identificar como as habilidades eram trabalhadas em 
VI Congresso Brasileiro de Informática na Educação (CBIE 2017)

Anais dos Workshops do VI Congresso Brasileiro de Informática na Educação (WCBIE 2017)

suas atividades junto aos alunos. Os dados coletados foram analisados qualitativamente, comparando as definições da literatura e as respostas do survey e da entrevista.

\section{Pensamento Computacional}

O termo Pensamento Computacional ganhou destaque no artigo seminal de Wing (2006). Ela argumentou que pensamento computacional envolve a resolução de problemas, a concepção de sistemas e compressão do comportamento humano, baseando-se nos fundamentos da Ciência da Computação. Trata-se ainda de um processo que utiliza abstração, recursividade e iteração para se modelar e criar artefatos, bem como outras competências da computação.

A Computer Science Teachers Association (CSTA) possui uma força tarefa que é encarregada de conceituar e propor diretrizes para o ensino do pensamento computacional nas escolas, a CSTA Computational Thinking Task Force (CSTA, 2011). Ela definiu nove habilidades que são primordiais para exercício do pensamento computacional. As nove habilidades são: (i) Coleta de Dados, uma técnica para reunião de dados para se obter informações; (ii) Análise de Dados, compreensão feita sobre o conjunto de informações coletadas; (iii) Representação de Dados, maneira como trabalhamos com os resultados obtidos, ou seja, por meio de representação de gráficos, tabelas, imagens etc; (iv) Decomposição de Problema, um procedimento de decompor os problemas em subpartes menores para se trabalhar com pequenas unidades do problema; (v) Abstração, capacidade de abstrair conceitos amplos, e focar na essência do objeto estudado para tentar compreendê-lo; (vi) Algoritmos e Procedimentos, uma sequência de passos para resolver problemas; (vii) Automação, o processo que inclui um dispositivo (máquinas e/ou ferramentas) que faça a automatização dos processos, seja eles manuais ou mentais; (viii) Paralelização, trabalhar com diversos recursos ao mesmo tempo, para obter um resultado em comum; e (ix) Simulação, representação ou execução de um processo.

\subsection{Pensamento Computacional no Ensino Escolar Brasileiro}

No Brasil, as iniciativas voltadas à promoção de pensamento computacional nas escolas são provenientes de projetos desenvolvidos nas universidades em muitos dos casos. Vemos ações de pesquisadores e professores de Computação que, através de projetos, desenvolvem tais conteúdos nas escolas. Isso acontece porque os currículos nacionais não contemplam o ensino de computação, mesmo que seus benefícios sejam comprovados sobre as práticas pedagógicas [Cambraia e Scaico, 2013].

Dentre as iniciativas recentes, França et al.(2014) realizaram um relato histórico de atividades desenvolvidas para estimular o ensino de computação no Brasil. Os autores destacaram as iniciativas de: (i) ensino de fundamentos da Ciência da Computação, principalmente através de atividades desplugadas, (ii) ensino de robótica e (iii) promoção do pensamento computacional de modo interdisciplinar por meio do 
VI Congresso Brasileiro de Informática na Educação (CBIE 2017)

Anais dos Workshops do VI Congresso Brasileiro de Informática na Educação (WCBIE 2017)

PIBID (Programa Institucional de Bolsa de Iniciação à Docência) das licenciaturas em Pedagogia, Letras, Matemática, Geografia, História.

\section{Trabalhos Relacionados}

Mannila et al. (2014) apresentaram a visão que os professores do K-9 (equivante ao ensino fundamental no Brasil) de diferentes países possuem a respeito do pensamento computacional em sua prática pedagógica. Os autores realizaram um survey com professores do K-9 de 6 países com o objetivo de identificar quais aspectos do pensamento computacional já fazem parte das práticas pedagógicas e como elas são realizadas. Os resultados apontaram que algumas práticas já são realizadas, mesmo sem a ciência por parte dos professores de que se trata de habilidade do pensamento computacional.

No Brasil, ainda são escassas as pesquisas sobre a compreenção do pensamento computacional por professores da educação básica, bem como por profissionais e estudantes de Computação. Farias, Andrade e Alencar (2015) aplicaram um questionário a alunos concluintes de um curso de Licenciatura em Computação com propósito de compreender o grau de ciência deles sobre a importância do pensamento computacional. Os resultados apontaram que estudantes possuem limitações conceituais sobre o pensamento computacional, apresentando respostas fundamentadas em crenças, as quais destoam dos conceitos e práticas da literatura.

Araújo, Andrade e Guerrero (2015) realizaram um survey com profissionais da computação no intuito de capturar a compreensão que eles possuem a respeitos do pensamento computacional. Os resultados apontaram que $64 \%$ dos pesquisados desconhecem o que o significado de pensamento computacional. Além disso, os resultados sugerem que o termo e as habilidades são pouco conhecidos e compreendidos pelos profissionais, tanto na indústria como na academia. Nesse contexto, vemos que estudantes e profissionais da computação ainda desconhecem pensamento computacional.

\section{Procedimentos e Métodos}

A abordagem desta pesquisa pode ser caracterizada como uma pesquisa de campo qualitativa. Para norteá-la, realizamos o levantamento bibliográfico para embasar os conceitos, habilidades e competências do pensamento computacional. Em seguida, planejamos e executamos um survey supervisionado e entrevistas com professores do ensino médio. $\mathrm{O}$ restante da seção detalha os participantes e os instrumentos.

\subsection{Participantes}

Todos os participantes desta pesquisa são professores do ensino média da Escola Estadual de Ensino Fundamental e Médio. A seleção dos participantes se deu por amostragem por conveniência e adesão à pesquisa. 
VI Congresso Brasileiro de Informática na Educação (CBIE 2017)

Anais dos Workshops do VI Congresso Brasileiro de Informática na Educação (WCBIE 2017)

Do survey supervisionado participaram 15 professores (41,6\% no número de professores efetivos da escola). Esses professores lecionam as seguintes disciplinas do ensino médio: 1 de Filosofia, Sociologia e História, 2 de Geografia, 2 de História, 1 de Física, 1 de Química, 1 de Matemática, 1 de Língua Portuguesa, 2 de Língua Estrangeira e 2 de Educação Física. Oito docentes são do sexo masculino e sete são do sexo feminino. Já em relação a idade, nove docentes possuem idade entre 30 a 50 anos, quatro a partir de 50 anos e dois com idade menor do que 30 anos.

Da entrevista, participaram seis professores que foram selecionados por conveniência. Eles lecionam as seguintes disciplinas: Geografia, Educação Física, História, Biologia, Matemática e Língua Estrangeira. Esses professores selecionados abrangem as área das Ciências Humanas e suas Tecnologias; Linguagens, Códigos e suas Tecnologias e das Ciências da Natureza, Matemática e suas Tecnologias. A escolha dessas áreas se deu pelo fato de tentarmos compreender a visão dos professores em cada grande área, uma vez que as habilidades do pensamento computacional podem ser desenvolvidas em cada uma delas, mas de maneiras distintas. Três professores foram do sexo masculino e três do sexo feminino.

\subsection{Instrumentos e Procedimentos}

O questionário aplicado no survey foi adaptado de (Manilla et al, 2014). Ele contém 11 questões, sendo 10 questões objetivas e uma subjetiva. Nove dessas questões objetivas abrangem as nove habilidades do pensamento computacional consideradas neste trabalho: coleta de dados, análise de dados, representação de dados, decomposição de problema, abstração, algoritmos, automação, paralelização e simulação. Cada questão apresentava a explicação da habilidade e solicitava que o professor selecionasse a frequência com que julgava explorar essas habilidades do pensamento computacional. A escala de frequência compreendia nas opções de: nem um pouco, um pouco, às vezes, na maioria das aulas, em todas as aulas. A questão subjetiva pedia para o professor descrever um exemplo de como uma das nove habilidades questionadas era utilizada em sala de aula. A décima questão objetiva do questionário pedia para o professor assinalar quais softwares, tecnologias ou outras ferramentas ele usa em sala. As questões do survey podem ser vistas na íntegra no link: https://goo.gl/5Jo5dp

Entrevistas foram realizadas após a aplicação dos questionários quando o professor consentia em participar da entrevista. A entrevista foi composta por dez questões, uma de cada habilidade, com exceção da habilidade de decomposição de problema, a qual foi elaborada duas questões. Tal decisão foi tomada, visto que nas respostas do questionário, decomposição foi a habilidade mais explorada pelos professores.

As questões da entrevista foram elaboradas pelos autores e estão disponíveis na íntegra no link https://goo.gl/FRbvZp. As questões foram elaboradas de maneira que não foi usada o nome da habilidade, e sim uma breve explicação da habilidade e o pedido 
VI Congresso Brasileiro de Informática na Educação (CBIE 2017)

Anais dos Workshops do VI Congresso Brasileiro de Informática na Educação (WCBIE 2017)

para que fosse citado um exemplo de aplicação na prática docente do professor. As entrevistas foram gravadas e transcritas para análise das respostas.

\section{Análises e Discussão dos Resultados}

Nesta seção apresentamos os resultados e discussão dos questionários e das entrevistas, bem como as ameaças à validade da pesquisa.

\subsection{Análises e Discussão do Questionário}

O questionário (survey) teve o objetivo de identificar quais habilidades do pensamento computacional são mais frequentemente utilizadas pelos professores do Ensino Médio durante a realização das atividades dentro ou fora da sala de aula.

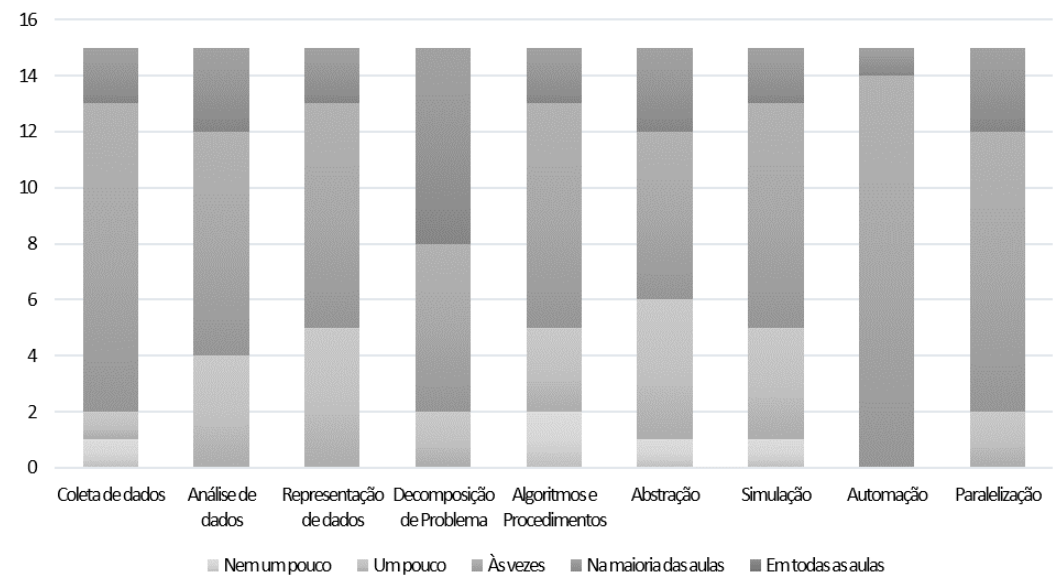

Figura 1. Frequência das habilidades respondidas no questionário

A Figura 1 apresenta um gráfico de barras com as respostas dos professores. Percebemos que nenhum dos professores mencionou utilizar as habilidades do pensamento computacional "Em todas as aulas". Porém, vemos indícios de que permite comparar as habilidades utilizadas em outras ocasiões. Ao analisar a resposta “Às vezes”, vemos que ela recebeu a maior quantidade de votos em todas as habilidades, com exceção de decomposição de problema, pois é a única entre todas que é utilizada "Na maioria das aulas" pelos professores. Ao analisar a resposta "Um pouco", a quantidade de votos ultrapassou os votos de algumas habilidades que são utilizadas "Na maioria das aulas". Tais habilidades foram: análises de dados, representação de dados, algoritmos e procedimentos, abstração e simulação. Já ao analisarmos os votos de "Nem um pouco" notamos, com base na Figura 1, que houve apenas uma única vez em que a quantidade de votos foi igual para umas das habilidades utilizadas "Na maioria das aulas", a qual foi algoritmos e procedimentos.

As respostas subjetivas foram analisadas e classificadas como "Possui relação" e "Não possui relação" com as habilidades do pensamento computacional. O critério para a classificação foi à identificação de ao menos uma habilidade na resposta do professor. 
VI Congresso Brasileiro de Informática na Educação (CBIE 2017)

Anais dos Workshops do VI Congresso Brasileiro de Informática na Educação (WCBIE 2017)

Sete respostas foram classificadas como "possui relação" e as habilidades encontradas foram: decomposição de problemas, simulação, abstração, automação, representação de dados. Das respostas que possuem relação com habilidade do pensamento computacional, podemos destacar as seguintes explicações dos professores: a) "Durante os seminários os alunos procuram dividir tarefas grandes em partes menores"; b) "Em trigonometria, utilizo o próprio espaço físico e com auxílio de planilhas ou Geogebra fazemos a demonstração"; c) "Encontrar características para criar modelos que ajudem a resolver alguns problemas enfrentados na sala de aula" , e d) "Dividir tarefas grandes em menores e usar um instrumento tecnológico para ajudar a realizar novas tarefas. Além de tornar a aula menos cansativa, desperta a curiosidade do aluno e facilita a absorção dos conteúdos".

\subsection{Análises e Discussão das Entrevistas}

A análise das respostas das entrevistas foi realizada com intuito de conhecer como os professores de fato exploram as habilidades do pensamento computacional durante as atividades didáticas em sala de aula. A análise e classificação das respostas foi baseada nas definições presentes no Computational Thinking Teacher Resources (2011) e em Barr e Stephenson (2011).

Para a habilidade de coleta de dados, um professor respondeu que realiza atividades nas quais os alunos precisam realizar pesquisas na internet. Já outro deu o seguinte exemplo de atividade: "Por exemplo: nós vamos trabalhar agora com sexualidade, então eu pedi a eles que (os alunos) fizessem uma pesquisa na escola mesmo, no turno da manhã, tarde e noite, perguntando - Quem já foi assediado sexualmente? Para que, com esses dados, nós possamos levar para sala de aula e ter uma breve discussão para poder chegar ao assunto em si". Nesse exemplo, vemos uma forma de trabalhar a coleta de dados.

Para a habilidade de análise de dados, no survey, os professores responderam que exploram essa habilidade "na maioria das aulas". Entretanto, na entrevista, apenas um professor tentou demonstrar que usava análise de dados. Lendo as outras respostas, temos indícios de que o conceito de análise de dados acaba perdendo o sentido do contexto de pensamento computacional, pois os professores afirmam realizar a interpretação de questões para o aluno. Já para a CSTA (2011, p. 14), análise de dados é visto como "dá sentido aos dados, categorizar, produzir e avaliar gráficos a partir de dados gerados".

Os professores associaram a habilidade de representação de dados como reproduzir filmes, analisar charges, imagens e textos ilustrativos. Entretanto, segundo a CSTA, representação de dados está mais relacionada à forma de organização desses dados e produção de gráficos, tabelas e imagens para representá-los. Para a habilidade de decomposição de problemas, destacamos a seguinte resposta: “... a gente começa 
VI Congresso Brasileiro de Informática na Educação (CBIE 2017)

Anais dos Workshops do VI Congresso Brasileiro de Informática na Educação (WCBIE 2017)

explicando: vá dividindo por parte essa questão para você conseguir compreender o todo. Então é um hábito mesmo nosso, e no caso, minha, é uma prática minha. Que quando a questão é complexa, muito grande, a gente ir trabalhando por partes". Pelo fato de ter sido a habilidade com maior frequência de votos no survey, esperávamos que as respostas fossem mais claras no tocante a dividir os problemas em tarefas menores. Entretanto, nas respostas dos outros professores, não conseguimos identificar claramente esses passos.

$\mathrm{Na}$ habilidade de algoritmos e procedimentos, não conseguimos identificar nenhum exemplo nas respostas dos professores. Já para a habilidade de abstração, as respostas dos professores conduzem os alunos a grifarem os dados os quais a questão solicita, ou ainda identificar as palavras-chaves da questão. Três professores associaram a habilidade de simulação à participação de aula de campo, na qual os alunos poderiam observar os assuntos teóricos trabalhos em sala. Entretanto, tal prática não possui relação direta com a definição de simulação apresentado na literatura de pensamento computacional. No tocante a habilidade de automação, o professor de inglês respondeu utilizar junto aos alunos ferramentas de tradução automática de texto. Nas demais respostas, os professores compreenderam que estimular os alunos a usarem o computador, tablet ou celular consistia em uma forma de automatizar tarefas.

Por último, na habilidade de paralelização, todos os professores responderam que estimulam essa habilidade com trabalhos em equipe. Um deles exemplificou assim: "Quando a gente trabalha em grupo maiores, né. Divide: você vai pesquisar tal assunto, você sobre tal assunto, e depois a gente vai unir está informações e trocar, nas apresentações dos seminários e tal'. Na fala do professor, vemos divisão de tarefas, embora não podemos concluir que há paralelização em sua totalidade, uma vez que, para a CSTA, paralelização é organizar recursos para efetuar tarefas simultaneamente para alcançar um objetivo comum, existindo planejamento, cronograma e divisão de atividades entre os membros. A forma como a pergunta da entrevista foi formulada pode ter interferido para não conseguir capturar a informação completa.

\subsection{Ameaças à Validade}

As limitações e ameaças à validade desta pesquisa estão relacionadas à quantidade da amostra pesquisada em única escola pública. Além disso, os professores podem não terem compreendido adequadamente as questões do questionário (survey) e da entrevista ou não terem conseguido recordar e/ou associar práticas pedagógicas no contexto das habilidades exploradas nas questões no momento da pesquisa.

\section{Considerações Finais}

Este trabalho exploratório buscou compreender a percepção dos professores do Ensino Médio sobre o pensamento computacional. Os métodos utilizados para atingir esse objetivo foram revisão bibliográfica, aplicação de questionários (survey) e entrevistas. 
VI Congresso Brasileiro de Informática na Educação (CBIE 2017)

Anais dos Workshops do VI Congresso Brasileiro de Informática na Educação (WCBIE 2017)

Os dados obtidos por meio dos instrumentos de coleta de dados foram analisados confrontando-os com as definições presentes na literatura.

Os resultados gerais apontaram que a percepção dos professores e as atividades relacionadas à cada habilidade nesta pesquisa foram: (i) a habilidade de coleta de dados ficou compreendida como realizar pesquisa na internet e coletar dados entrevistando pessoas; (ii) análise de dados não foi identificada com clareza; (iii) representação de dados foi assimilada pelos professores como apresentar filmes e imagens durante as atividades; (iv) a decomposição de problema ficou associada à dividir questões em pequenas partes; (v) algoritmos e procedimentos não foram identificados; (vi) abstração ficou compreendida como identificar o que uma questão pede como resposta e as informações relevantes do enunciado; (vii) simulação, para alguns foi utilizar ferramentas para simular (como planilha eletrônica), outros associaram simulação com participar de aula de campo; (viii) automação ficou associada a usar ferramentas de tradução automática de textos, outros professores associaram ao uso de tablet, celular e computador; por último, (ix) paralelização ficou associada a fazer trabalho em equipe, mesmo não ficando claro se há organização dos recursos para que se permita efetuar as tarefas simultaneamente, para assim, chegar a um objetivo comum.

Com base nos dados analisados com vistas à literatura, temos indícios que as habilidades do pensamento computacional ainda são pouco exploradas no grupo de professores pesquisados. Esse resultado pode ser ocasionado pela não compreensão do conceito e das habilidades relacionadas ao pensamento computacional. Essa explicação se torna mais evidente quando observamos que alunos concluintes e profissionais da Computação desconhecem pensamento computacional ou possuem conhecimentos equivocados, não condizentes com a literatura, como apontado nos trabalhos relacionados. Somado a isso, a falta de uma formação adequada em pensamento computacional voltada aos professores da educação básica pode ser uma das causas para o desconhecimento sobre como abordá-lo em práticas pedagógicas nas disciplinas.

Outros trabalhos futuros podem conduzidos nas vertentes de: (i) realizar nova coleta de dados em diferentes escolas, envolvendo ensino público e privado; (ii) expandir a coleta de dados para professores do ensino fundamental e comparar os resultados obtidos; (iii) analisar o uso das habilidades do pensamento computacional por disciplinas e comparar se uma área temática explora um maior conjunto de habilidades em comparação a outra.

\section{Referências}

ARAUJO, A. L., ANDRADE, W., \& SEREY, D. (2015). Pensamento Computacional sob a visão dos profissionais da computação: uma discussão sobre conceitos e habilidades. In: IV Anais dos Workshops do Congresso Brasileiro de Informática na Educação.

BARR, Valerie; STEPHENSON, Chris. (2009). Bringing computational thinking to $K$ - 
VI Congresso Brasileiro de Informática na Educação (CBIE 2017)

Anais dos Workshops do VI Congresso Brasileiro de Informática na Educação (WCBIE 2017)

12: what is Involved and what is the role of the computer science education community?. Acm Inroads, v. 2, n. 1, p. 48-54, 2011.

BLIKSTEIN, Paulo. (2008). O pensamento computacional e a reinvenção do computador na educação. Disponível em < http://www.blikstein.com/paulo/documents/online/ol_pensamento_computacional.ht ml> Acesso em: 02 de set. 2017.

CAMBRAIA, Adão Caron; SCAICO, Pasqueline Dantas. (2013). Os desafios da Educação em Computação no Brasil: um relato de experiências com Projet os PIBID no Sul e Nordeste do país. Revista Espaço Acadêmico, v. 13, n. 148, p. 01-09.

CAMPOS, Gleider M. et al. (2014) Organização de Informações via Pensamento Computacional: Relato de Atividade Aplicada no Ensino Fundamental. In: Anais do Workshop de Informática na Escola.

Computational Thinking Teacher Resources. (2011). Disponível em: https://csta.acm.org/Curriculum/sub/CurrFiles/472.11CTTeacherResources 2ed-SPvF.pdf. Acesso em: 12 fev 2017.

CSTA. Computer Science Teachers Association Computational Thinking Task Force. Disponível em: < https://csta.acm.org/Curriculum/sub/CompThinking.html> Acesso em: 15 fev. 2017.

FARIAS, A., ANDRADE, W., \& ALENCAR, R. (2015). Pensamento Computacional em Sala de Aula: Desafios, Possibilidades e a Formação Docente. In: IV Anais dos Workshops do Congresso Brasileiro de Informática na Educação.

FRANÇA, R. S., FERREIRA, V. F. S., ALMEIDA, L. D., \& AMARAL, H. D. (2014). A disseminação do pensamento computacional na educação básica: lições aprendidas com experiências de licenciandos em computação. In: Anais do XXII Workshop sobre Educação em Computação (WEI-CSBC).

MANNILA, L., DAGIENE, V., DEMO, B., GRGURINA, N., MIROLO, C., ROLANDSSON, L., \& SETTLE, A. (2014). Computational thinking in K-9 education. In: Proceedings of the Working Group Reports of the 2014 on Innovation \& Technology in Computer Science Education Conference (pp. 1-29). ACM.

SCAICO, Pasqueline Dantas et al. (2012). Relato da Utilização de uma Metodologia de Trabalho para o Ensino de Ciência da Computação no Ensino Médio. In: Anais do Workshop de Informática na Escola. 2012.

VIEIRA, Anacilia; PASSOS, Odette; BARRETO, Raimundo (2013). Um relato de experiência do uso da técnica computação desplugada. Anais do XXI Workshop sobre Educação em Informática. p. 670-679.

WING, J. M. (2006). Computationalthinking. Communications ofthe ACM, v. 49, n. 3, p. 33-35, 2006. 